Volume 16, No. 1, Januari 2019

Page: 743-746

\title{
HUBUNGAN PENGETAHUAN DAN SIKAP KARYAWAN PERKEBUNAN KELAPA SAWIT DENGAN PERILAKU AMAN
}

\author{
Muhammad Reza Amrullah, Arifin, Maharso \\ Poltekkes Kemenkes Banjarmasin Jurusan Kesehatan Lingkungan \\ Email: rezaalimaki14@gmail.com
}

\begin{abstract}
The Relations Of Oil Palm Plantations Employee Knowledge and Attitude With Safety Behaviour. The Efforts to implement safety and health at work, Based on the results of the study showed that the work accident in the plantation related with the form of working operations in the plantations begin from the process of replanting, planting, plant maintenance to the production process. The purpose of the research is to find the relations Of Oil Palm Plantations Employee Knowledge and Attitude With Safety Behaviour in PT. GMK West Plantation Batu Ampar Sub-district Tanah Laut Regency, the benefit of this research is as an information and evaluation material to know the factors influencing employees with the relations of safety behavior.The research method used is an analytical survey with cross sectional approach, the population in this study amounted to 540 people, and the sample is 50 people. Data analysis is using test (Chi-Square).The results of the study showed: (1) good knowledge 90\%, (2) good attitude 60\%, (3) good behavior 60\%, (4) knowledge $(p=0,643)$, (5) attitude $(p=0,000)$. There is no relations of knowledge and there is a relations of oil palm plantation employee attitude with safety behavior in PT. GMK West Plantation Batu Ampar Sub-District Tanah Laut Regency.
\end{abstract}

Keywords: Knowledge; Attitude; Safety Behaviour

Abstak: Hubungan Pengetahuan dan Sikap Karyawan Perkebunan Kelapa Sawit dengan Perilaku Aman. Upaya penerapan keselamatan dan kesehatan kerja, Berdasarkan hasil studi menunjukkan bahwa kecelakaan kerja di perkebunan terkait dengan bentuk operasi kerja di perkebunan mulai dari proses replanting, penanaman, pemeliharaan tanaman sampai proses produksi. Tujuan penelitian adalah hubungan pengetahuan dan sikap karyawan perkebunan kelapa sawit dengan perilaku aman (safety behavior) di PT. GMK Kebun Barat Kecamatan Batu Ampar Kabupaten Tanah Laut, manfaat penelitian ini adalah sebagai bahan informasi dan evaluasi untuk mengetahui faktor mempengaruhi karyawan hubungannya dengan perilaku aman.Metode penelitian yang digunakan adalah survey analitik dengan pendekatan cross sectional, populasi dalam penelitan ini berjumlah 540 orang, dan sampel sebanyak 50 orang. Analisis data menggunakan uji $X^{2}$ (Chi-Square).Hasil uji penelitian menunjukan :(1) pengetahuan baik 90\%,(2) sikap baik 60\%, (3) perilaku baik 60\%, (4) pengetahuan (p=0,643), (5) Sikap $(p=0,000)$.menunjukan tidak ada hubungan pengetahuan dan ada hubungan sikap karyawan perkebunan kelapa sawit dengan perilaku aman di PT. GMK Kebun Barat Kecamatan Batu Ampar Kabupaten Tanah Laut.

Kata kunci: Pengetahuan; sikap; perilaku aman

\section{PENDAHULUAN}

Indonesia adalah Negara yang beriklim tropis dan memiliki tanah yang subur sehingga dikenal sebagai Negara agraris. Dengan kondisi alam tersebut, tidak heran pemerintah menggala kan pengembangan usaha Negara pada unit pertanian dan perkebunan. Sumber daya manusia memegang peranan penting bagi keberhasilan suatu organisasi atau perusahaan, karena manusia merupakan aset hidup yang perlu diperhatikan secara khusus oleh perusahaan. Selain kinerja karyawan, dalam manajemen sumber daya manusia, terdapat pula salah satu hal yang harus menjadi perhatian yaitu sistem keselamatan dan kesehatan kerja[1].

Data ILO pada tahun 2015 mencatat, setiap hari terjadi sekitar 6.000 kecelakaan kerja fatal di dunia. Di 
Indonesia sendiri, terdapat kasus kecelakaan yang setiap harinya dialami para buruh dari setiap 100 ribu tenaga kerja. Berdasarkan hasil studi menunjukkan bahwa kecelakaan kerja di perkebunan terkait dengan bentuk operasi kerja di perkebunan mulai dari proses replanting, penanaman, pemeliharaan tanaman sampai proses produksi. Temuan penting menunjukkan bidang kerja yang paling rentan terhadap resiko kecelakaan adalah karyawan bagian pemanen.

PT. Gawi Makmur Kalimantan Barat Estate merupakan perusahaan yang bergerak dibidang perkebunan kelapa sawit. Pada tahun 2016 pada setiap bulan terjadi 2 kali kecelakaan kerja jadi pada dua belas bulan bisa terjadi kecelakaan kerja sebanyak 24 kali, kecelakaan kerja itu banyak terjadi pada tahapan panen yaitu kecelakaan terkena pelepah kelapa sawit, pada semua tahapan pekerjaan karyawan sudah memakai APD lengkap namun pada tahapan panen karyawan kurang memiliki kesadaran untuk memakai APD. Terkait dengan pengetahuan dan sikap karyawan perkebunan kelapa sawit.

\section{BAHAN DAN CARA PENELITIAN}

Populasi penelitian ini adalah seluruh karyawan perkebunan PT.GMK Kebun Barat Kecamatan Batu Ampar Kabupaten Tanah Laut yang berjumlah 540 orang karyawan. Pada penelitian ini sampel yang digunakan adalah karyawan perkebunan PT. GMKKebun Barat Kecamatan Batu Ampar Kabupaten Tanah Laut dengan jumlah atau besaran sampel dihitung menggunakan rumus estimasi proporsi pada sampel acak sederhana dengan presisi mutlak [2] jumlah sampel penelitian yang diperlukan sebanyak 50 orang karyawan.

Teknik pengambilan sampel yang digunakan adalah metode proportionate stratified random sampling. Digunakan bila populasi mempunyai anggota/unsur yang tidak homogen dan berstrata secara proporsional [3]. Analisis data berupa analisis univariat dan analisis bivariat.
Metode pengumpulan data penelitian ini dengan cara : data primer: pengetahuan, sikap karyawan, perilaku aman. Data sekunder : Data sekunder yaitu berupa jumlah karyawan, profil perkebunan, serta data pendukung lainnya.

Data yang diperoleh diolah secara manual, disajikan dalam bentuk tabel distribusi frekuensi. Untuk mengetahui hubungan pengetahuan dan sikap karyawan perkebunan kelapa sawit dengan perilaku aman (safety behavior) di PT. GMK Kebun Barat Kecamatan Batu Ampar Kabupaten Tanah Laut, dianalisis dengan menggunakan perhitungan statistik yaitu dengan bantuan komputer dengan Uji X² (Chi-Square).

\section{HASIL PENELITIAN DAN PEMBAHASAN}

Sebagian besar karyawan di PT. GMK Kebun Barat memiliki umur 35-50 tahun sebanyak $72 \%$. Masa kerja karyawan lebih banyak yang memiliki masa kerja diatas 5 tahun 62\%. 54\% karyawan berpendidikan menengah, dan tidak ada karyawan yang lulus perguruan tinggi.

Karyawan yang memiliki pengetahuan baik tentang perilaku aman sebanyak 90\%. Penelitian yang sejenis juga dilakukan oleh Siti Halimah menganalisa faktor-faktor yang mempengaruhi perilaku aman karyawan dalam penggunaan APD bahwa pengetahuan sebagian besar di dapat pada saat setelah bekerja di perkebunan tersebut. Namun, walaupun bahaya risiko saat melakukan semua tahapan pekerjaan serta kegunaan dari APD, masih banyak karyawan yang tida menggunakan APD yang baik pada saat bekerja[4].

Karyawan yang memiliki sikap baik tentang perilaku aman sebanyak $60 \%$. Sikap merupakan suatu kecenderungan untuk mengadakan tindakan terhadap suatu objek, dengan suatu cara yang menyatakan adanya tanda untuk menyenangi atau tidak menyenangi objek tersebut[5].

Karyawan yang menggunakan APD lebih besar disbanding dengan karyawan yang 
tidak menggunakan APD yaitu sebesar $60 \%$. Penelitian yang sejenis juga dilakukan oleh Siti Halimah yaitu faktorfaktor yang mempengaruhi perilaku aman karyawan Di PT. SIM PLANT Tambun diketahui $89,9 \%$ karyawan berperilaku aman dan 16,2\% karyawan yang tidak berperilaku aman ${ }^{[4]}$.

Tabel 1. Hubungan Pengetahuan Karyawan dengan Perilaku Aman (safety behavior)

Perilaku Aman

\begin{tabular}{cccccccc} 
No & Pengetahuan & \multicolumn{2}{c}{ Tidak Baik } & \multicolumn{2}{c}{ Baik } & \multicolumn{2}{c}{ Total } \\
& & \multicolumn{1}{c}{} & & & & \\
\hline & & $\mathrm{n}$ & $\%$ & $\mathrm{n}$ & $\%$ & $\sum$ & $\%$ \\
1 & Baik & 19 & 42,3 & 26 & 57,7 & 45 & 100 \\
2 & Kurang Baik & 3 & 60 & 2 & 40 & 5 & 100 \\
& Total & 22 & 44 & 28 & 56 & 50 & 100 \\
\hline
\end{tabular}

Berdasarkan tabel tersebut dapat diketahui dari karyawan yang memiliki pengetahuan kurang baik $60 \%$ yang tidak menggunakan APD pada saat melakukan tahapan pekerjaan.

Hasil uji statistik dilakukan dengan Uji X ${ }^{2}$ (Chi-Square) bahwa nilai $\mathrm{p}>0,05 p$ value sebesar 0,776, maka Ho diterima yang artinya tidak cukup bukti secara statistik untuk menyatakan ada hubungan pengetahuan karyawan perkebunan dengan perilaku aman (safety behavior). Penelitian ini sependapat dengan Hastanti (2004) yang menyatakan bahwa tidak ada hubungan antara pengetahuan dengan pemakaian APD.[6]

Tabel 2. Hubungan Antara Sikap Karyawan dengan Perilaku Aman (safety behavior) Perilaku Aman

\begin{tabular}{cccccccc} 
No & Sikap & \multicolumn{2}{c}{ Tidak Baik } & \multicolumn{2}{c}{ Baik } & \multicolumn{2}{c}{ Total } \\
& & & & & & \\
\hline & & $\mathrm{n}$ & $\%$ & $\mathrm{n}$ & $\%$ & $\sum$ & $\%$ \\
1 & Setuju & 2 & 6,6 & 28 & 93,3 & 30 & 100 \\
2 & Tidak setuju & 20 & 100 & 0 & 0 & 20 & 100 \\
& Total & 22 & 44 & 28 & 56 & 50 & 100 \\
\hline
\end{tabular}

Berdasarkan tabel tersebut dapat diketahui hasil seluruh karyawan yang mempunyai sikap baik pada saat bekerja menggunakan APD sebanyak 93,3\%,dan karyawan yang mempunyai sikap kurang baik, tidak ada satupun yang menggunakan APD saat melaksanakan tahapan pekerjaan.

\section{KESIMPULAN DAN SARAN}

Pengetahuan responden tentang perilaku aman (safety behavior) pengetahuan yang kurang baik tentang perilaku aman berjumlah 5 orang (10\%). dan yang memiliki pengetahuan baik
Hasil uji statistik dilakukan dengan Uji $\mathrm{X}^{2}$ (Chi-Square) bahwa nilai $\mathrm{p}<0,05 p$ value sebesar 0,000, maka Ho ditolak yang artinya cukup bukti secara statistik untuk menyatakan bahwa ada hubungan sikap karyawan perkebunan dengan perilaku aman (safety behavior)

berjumlah 45 orang (90\%), sikap responden tentang perilaku aman (safety behavior) sikap yang kurang baik tentang perilaku aman berjumlah 20 orang (40\%). dan yang memiliki sikap baik berjumlah 30 
orang (60\%). Perilaku Aman (safety behavior), yaitu berjumlah 20 orang (40\%) yang tidak menggunakan APD dan sebanyak 30 orang (60\%) yang menggunakan APD.

Dari hasil uji statistik chi-square diperoleh nilai $p$ value sebesar 0,776 (p > $0,05)$ maka Ho diterima yang artinya tidak cukup bukti secara statistik untuk menyatakan ada hubungan pengetahuan karyawan perkebunan dengan perilaku aman (safety behavior) di PT. GMK Kebun Barat Kecamatan Batu Ampar Kabupaten Tanah Laut. Berdasarkan hasil uji statistik menggunakan uji chisquare, di peroleh $p$ value sebesar $0,000(\mathrm{p}<0,05)$ maka Ho ditolak yang artinya cukup bukti secara statistik untuk menyatakan bahwa ada hubungan sikap karyawan perkebunan dengan perilaku aman (safety behavior) di PT. GMK Kebun Barat Kecamatan Batu Ampar Kabupaten Tanah Laut.

Karyawan yang masih tidak berperilaku aman saat melaksanakan tahapan pekerjaan, agar diberi motivasi sehingga mau bereperilaku aman saat melaksanakan pekerjaan. Bahkan dapat diberi sanksi agar mau melaksanakan perilaku aman, karyawan yang pengetahuan nya baik hendaknya dipertahankan dan mampu mempengaruhi serta membentuk sikap karyawan lain menjadi lebih baik dan mau beperilaku aman saat melaksakan pekerjaan. Manajemen Perkebunan kelapa sawit harus melaksanakan pengawasan yang dilaksanakan oleh Kepala Divisi terhadap karyawan perkebunan yang sedang melaksanakan tahapan pekerjaan untuk menguragi terjadinya kecelakaan kerja. Memberikan sanksi kepada karyawan perkebunan jika tidak berperilaku aman/ tidak menggunakan APD saat melaksanakan pekerjaan. Apabila masih mengulangi diberikan sanksi yang lebih berat dan melakukan rotasi pada mandor setiap divisi agar pengawasan lebih optimal, karena mungkin pengawasan mandor yang biasa dilaksanakan kurang optimal karena sudah terbiasa dengan kondisi setempat.

\section{KEPUSTAKAAN}

1. Hanggraeni, Dewi 2012. Manajemen Sumber Daya Manusia. Jakarta: Grasindo

2. Kasjono, H. S., dan Yasril. 2009. Teknik Sampling Untuk Penelitian Kesehatan. Edisi Pertama. Yogyakarta: Graha Ilmu.

3. Sugiyono.(2012). Metode Penelitian Kombinasi (Mixed Methods).

Bandung: Alfabeta.

4. Halimah Siti. 2010. FaktorfaktorPerilaku Yang Mempengaruhi Perilaku Aman Karyawan di PT. SIM PLANT TAMBUN II Tahun 2010. Skripsi.Jakarta : FKM UIN.

5. Notoatmodjo, S. (2003).Ilmu Kesehatan Masyarakat PrinsipPrinsip Dasar. Rineka Cipta.

6. Hastanti, Rulia. 2004. Faktor yang Berhubungan dengan Pemakaian APD Pada Pekerja Konstruksi Bangunan. Skripsi; Surabaya FKM Universitas Airlangga. 